\title{
Review: advances in in situ and satellite phenological observations in Japan
}

\author{
Shin Nagai ${ }^{1} \cdot$ Kenlo Nishida Nasahara ${ }^{2}$ Tomoharu Inoue ${ }^{1}$ - Taku M. Saitoh ${ }^{3}$. \\ Rikie Suzuki ${ }^{1}$
}

Received: 5 June 2015 /Revised: 14 August 2015 / Accepted: 14 August 2015 / Published online: 26 August 2015

(C) ISB 2015

\begin{abstract}
To accurately evaluate the responses of spatial and temporal variation of ecosystem functioning (evapotranspiration and photosynthesis) and services (regulating and cultural services) to the rapid changes caused by global warming, we depend on long-term, continuous, near-surface, and satellite remote sensing of phenology over wide areas. Here, we review such phenological studies in Japan and discuss our current knowledge, problems, and future developments. In contrast with North America and Europe, Japan has been able to evaluate plant phenology along vertical and horizontal gradients within a narrow area because of the country's high topographic relief. Phenological observation networks that support scientific studies and outreach activities have used nearsurface tools such as digital cameras and spectral radiometers. Differences in phenology among ecosystems and tree species have been detected by analyzing the seasonal variation of red, green, and blue digital numbers (RGB values) extracted from phenological images, as well as spectral reflectance and vegetation indices. The relationships between seasonal variations in RGB-derived indices or spectral characteristics and the ecological and $\mathrm{CO}_{2}$ flux measurement data have been well validated. In contrast, insufficient satellite remote-sensing observations have been conducted because of the coarse spatial
\end{abstract}

Shin Nagai

nagais@jamstec.go.jp

1 Department of Environmental Geochemical Cycle Research, Japan Agency for Marine-Earth Science and Technology (JAMSTEC), 3173-25 Showa-machi Kanazawa-ku, Yokohama 236-0001, Japan

2 Faculty of Life and Environmental Sciences, University of Tsukuba, Tsukuba 305-8572, Japan

3 River Basin Research Centre, Gifu University, Gifu 501-1193, Japan resolution of previous datasets, which could not detect the heterogeneous plant phenology that results from Japan's complex topography and vegetation. To improve Japanese phenological observations, multidisciplinary analysis and evaluation will be needed to link traditional phenological observations with "index trees," near-surface and satellite remote-sensing observations, "citizen science" (observations by citizens), and results published on the Internet.

Keywords Remote sensing · Phenology $\cdot$ Japan · Phenological observation network · Biometeorology

\section{Introduction}

To accurately evaluate changes in the spatial and temporal variation of ecosystem functioning (e.g., evapotranspiration, photosynthesis) and services (e.g., regulating, cultural) under the rapid climate changes that are occurring due to global warming, long-term, continuous, and broad-scale phenological observations are required (Richardson et al. 2013). The spatial and temporal variations of the timing of leaf flush and leaf fall affect biogeochemical processes such as $\mathrm{CO}_{2}$ uptake during photosynthesis and the emission of biogenic volatile organic compounds (Peñuelas et al. 2009; Polgar and Primack 2011; Keenan et al. 2014) and carbon, water, and heat budgets through the effects on evapotranspiration and physical properties such as latent and sensible heat, albedo, and the aerodynamic roughness of the land surface (Peñuelas et al. 2009; Polgar and Primack 2011; Schwartz et al. 2013). A phenological mismatch between plants and their animal pollinators and consumers may increase the risk of losses of biodiversity and supporting services (SCBD 2010; Polgar and Primack 2011; Kudo 2014). Under the future warming that is predicted to occur, the time lag between the blossoming date of species such 
as cherry (Prunus spp.) and the dates of associated festivals may disrupt tourism activities. To prevent the loss of cultural services such as flower tourism, decision-makers must develop adaptation plans (Sparks 2014).

Many previous studies examined the spatial and temporal variation of phenology based on fixed-point visual observations of "index trees" by experts (Linderholm 2006; OgawaOnishi and Berry 2013). Such observations have the merit of permitting long-term detailed phenological records. However, this method is labor-intensive (Richardson et al. 2007), the detection of phenological stages is subjective, the numbers of species and individuals that can be surveyed are limited, the observations fail to cover the full range of the species (they are mainly distributed in cities and low-altitude areas), and the observations may be affected by urbanization (e.g., the heat island effect; Ohashi et al. 2012). To solve these problems, we can take advantage of in situ (near-surface) and satellite remote sensing, which permit more objective, long-term, continuous phenological observations of many individuals over a wide area (Linderholm 2006; Morisette et al. 2009).

Long-term continuous phenological observations with digital cameras and spectral radiometers have been conducted since around 2003 for a range of ecosystems, mainly by American and Japanese networks. In the USA, this has been done by the PhenoCam network (http://phenocam.sr.unh.edu/ webcam/. Accessed 12 August 2015; Richardson et al. 2007); in Japan, it has been done by the Phenological Eyes Network (PEN; http://www.pheno-eye.org. Accessed 12 August 2015; Nasahara and Nagai 2015). However, these observations cover a limited area. Satellite remote sensing of vegetation indices, such as the data from the Advanced Very High Resolution Radiometer (AVHRR) sensor onboard National Oceanic and Atmospheric Administration (NOAA) satellites since 1981, can detect the spatial and temporal variation of phenology at large scales (Delbart et al. 2006; Buitenwerf et al. 2015). Furthermore, the Moderate-resolution Imaging Spectroradiometer (MODIS) sensors onboard the Terra and Aqua satellites have provided phenological data since 2000, and the VEGETATION sensor onboard the Satellite Pour l'Observation de la Terre (SPOT) have provided data since 1999 at point, regional, and continental scales, with a resolution of 500 to $1000 \mathrm{~m}$ (Delbart et al. 2006; Nagai et al. 2015b).

Japan includes subarctic to subtropical zones, and $70 \%$ of the land is mountainous. The mountainous region in central Japan ranges widely in altitude (by 2000 to $3000 \mathrm{~m}$ ) over relatively short distances $(50 \mathrm{~km})$. Japan's maritime climate is strongly influenced by global atmospheric patterns such as the El Niño-Southern Oscillation and the Arctic Oscillation (JMA 2014). These geographical characteristics create large regional differences and diversity and high spatial variation of vegetation (Natural Environmental Information GIS 1999). For this reason, we require not only phenological observations based on index trees but also quantitative satellite data that cover many ecosystems and plant species over a wide area, with low labor costs, to obtain and process the data.

In this review, we describe plant phenological observations in Japan based on remote sensing and discuss our current knowledge, problems, and future developments based on these studies. The geography of Japan allows for evaluation of the spatial and temporal variation of plant phenology along vertical (altitude) and horizontal (latitude) gradients over short distances (Doi and Takahashi 2008; Matsumoto 2010; Nagai et al. 2015b). Nagai et al. (2015b) found that the spatial and temporal variations of the timing of the start and end of the deciduous forest's growing season were strongly affected by both vertical and horizontal gradients. In addition, the Japanese Ministry of the Environment, Forestry Agency and other organizations have surveyed the vegetation cover and forest structure throughout the country for many years (Natural Environmental Information GIS 1999). This geographical and social background suggests the possibility of taking advantage of a large body of evidence to accurately evaluate the spatial and temporal variation of plant phenology. In this review, we will not discuss previous agricultural and horticultural studies because the effects of human manipulations may conceal the effects of climate change.

\section{Background for Japanese phenological observations}

The dramatic lifestyle changes since World War II (rapid urbanization) drastically reduced opportunities to experience nature. However, citizens continue to enjoy viewing of spring cherry blossoms (hanami; Aono and Kazui 2008), which has been recorded since the ninth century $\mathrm{AD}$, and maple leaves (Acer spp.) in autumn (momiji-gari; Aono and Tani 2014), which has been recorded since the tenth century AD, because these activities are part of Japan's traditional culture. Recently, meteorological and tourist services, city offices, and tourist associations have published phenological information such as flowering and leaf coloring dates at scenic spots, resorts, temples, shrines, and parks on their Web sites. The Internet has dramatically increased the availability of such phenological information (Nagai et al. 2015a). Social networks such as Twitter and Facebook also let citizens share phenological information.

To find and experience these seasonal changes, citizens travel to scenic spots to view flowers and leaf coloring. Although technological crop cultivation (e.g., in greenhouses) and imported foods have undermined the sense of seasonality, citizens nonetheless receive nature's bounty (supporting ecosystem services) by purchasing seasonal vegetables and fruits. Seasonal events such as the timing of flowering and appearance of insects and birds have been important in Japanese literature, including classical poetry (waka) and haiku, since ancient times. Japanese citizen scientists have actively conducted 
phenological observations. "Ikimono Log," managed by the Biodiversity Center of Japan, is a major system for collecting and sharing biological information (http://ikilog.biodic.go.jp. Accessed 12 August 2015). These cultural, historical, and social backgrounds have created favorable conditions for Japanese phenological observations.

\section{Phenological observations using index trees}

In this section, we will briefly summarize previous phenological studies based on observations of index trees. Ogawa-Onishi and Berry (2013) provide detailed descriptions of Japanese studies. Typical data include the timing of flowering, leaf flush, leaf coloring, and leaf fall that have been published by meteorological agencies (Matsumoto et al. 2003; Doi and Takahashi 2008; Ibáñez et al. 2010; Matsumoto 2010). This dataset has been compiled at weather stations throughout Japan since 1953 (JMA 1985). In addition, long-term continuous observations of these parameters have been conducted at research forests and agricultural experiment stations (Miller-Rushing et al. 2007; Fujisawa and Kobayashi 2010).

Japan stretches more than $3000 \mathrm{~km}$, from $45^{\circ} \mathrm{N}$ to $20^{\circ} \mathrm{N}$ and from $123^{\circ} \mathrm{E}$ to $154^{\circ} \mathrm{E}$, and comprises nine climatic divisions (Suzuki 1962). This allows mapping of the spatial characteristics of the timing of flowering, leaf flush, leaf coloring, and leaf fall in each season and examination of the changes in timing in response to climate change (JMA 1985). By way of example, Fig. 1 shows the spatial distribution of the first flowering date of cherry (Prunus $\times$ yedoensis; somei-yoshino) in 2014, and Table 1 provides details of these data. Global warming has advanced blooming of this cherry by 5 days from 1953 to 2013 (JMA 2014) and leaf coloring of Ginkgo biloba by 4 days from 1953 to 2000 (Matsumoto et al. 2003), but has delayed leaf coloring of Acer palmatum by 18 days from 1953 to 2013 (JMA 2014) and leaf fall of G. biloba by 8 days from 1953 to 2000 (Matsumoto et al. 2003). Unlike the case in North America and Europe, Japan's delay in autumn phenology has been clearer than the advance in spring phenology (Matsumoto et al. 2003; Ibáñez et al. 2010; Matsumoto 2010).

\section{Japanese phenological observation networks}

Recently, automatic fixed-point phenological observations using near-surface remote-sensing techniques such as digital cameras and spectral radiometers have been conducted to support research and outreach activities. Typical networks include the Internet Nature Information System (INIS) in national parks across the country, managed by the Biodiversity Center of Japan (http://www.sizenken.biodic.go.jp. Accessed 12 August 2015; Ide and Oguma 2010), PEN at ecosystem study sites (http://www.pheno-eye.org. Accessed 12 August
2015; Nasahara and Nagai 2015), and Cyberforest, which mainly supports university forest research (http:/landscape. nenv.k.u-tokyo.ac.jp/cyberforest/Welcome.html. Accessed 12 August 2015; Saito et al. 2004). These networks have published daily phenological images on their Web sites. In addition, PEN has conducted automatic fixed-point spectral measurements of the canopy surface in forests and grasslands to provide vegetation index data (Nasahara and Nagai 2015).

The main aims of these systems were to introduce national parks to citizens through outreach activities (Ide and Oguma 2010), permit ground truthing of satellite remote-sensing data (Nasahara and Nagai 2015), and improve environmental education (Saito et al. 2004). INIS targets the landscape scale (200 to $1000 \mathrm{~m}$ ), whereas PEN and Cyberforest aim for coverage from shoot to landscape scales $(20 \mathrm{~cm}$ to $200 \mathrm{~m}$; Saito et al. 2004; Ide and Oguma 2010; Nasahara and Nagai 2015). Figure 2 summarizes the locations of the sites in each phenological observation network.

\section{Phenological observations by digital cameras and spectral radiometers}

\section{Digital cameras}

We can detect differences in plant phenological characteristics among ecosystems and tree species by analyzing the temporal variations in the red, green, and blue (RGB) digital numbers extracted from daily digital images (Richardson et al. 2007; Ide and Oguma 2010). These analyses have been conducted by INIS and PEN in various ecosystems (Ide and Oguma 2010; Nasahara and Nagai 2015). At some study sites, continuous daily phenological images exist for more than 10 years. Target ecosystems have been typical Japanese vegetated landscapes. Accordingly, the studies provide ground truthing data for phenological observations obtained by satellite remote sensing. However, some typical vegetation types such as oak (Quercus serrata) and mangrove (Rhizophoraceae spp.) forests have not yet been analyzed. In addition, Cyberforest has not conducted this analysis. Table 2 summarizes the previous studies that have been conducted in each Japanese ecosystem.

The year-to-year variation in the timing of flowering, leaf flush, and leaf fall for the whole canopy and for each tree species in deciduous forests can be detected by analyzing RGB time series (Ide and Oguma 2010; Nagai et al. 2011a; Inoue et al. 2014). The seasonal variation of these values correlates well with that of gross primary production (GPP) in this forest (Saitoh et al. 2012), deciduous coniferous forest (larch (Larix kaempferi) forest; Ide and Oguma 2011), and evergreen coniferous forest (Japanese cedar forest; Saitoh et al. 2012; Nagai et al. 2013a). Nagai et al. (2013a) examined differences between the seasonal variation in RGB-derived indices between a Japanese closed canopy evergreen 
Fig. 1 Spatial distribution of the first flowering date (day of year) of cherry (Prunus $\times$ yedoensis) in 2014. Data obtained nearby the 58 weather stations conducted by the Japan Meteorological Agency were published on the Internet. See Table 1 for details. DOY day of year

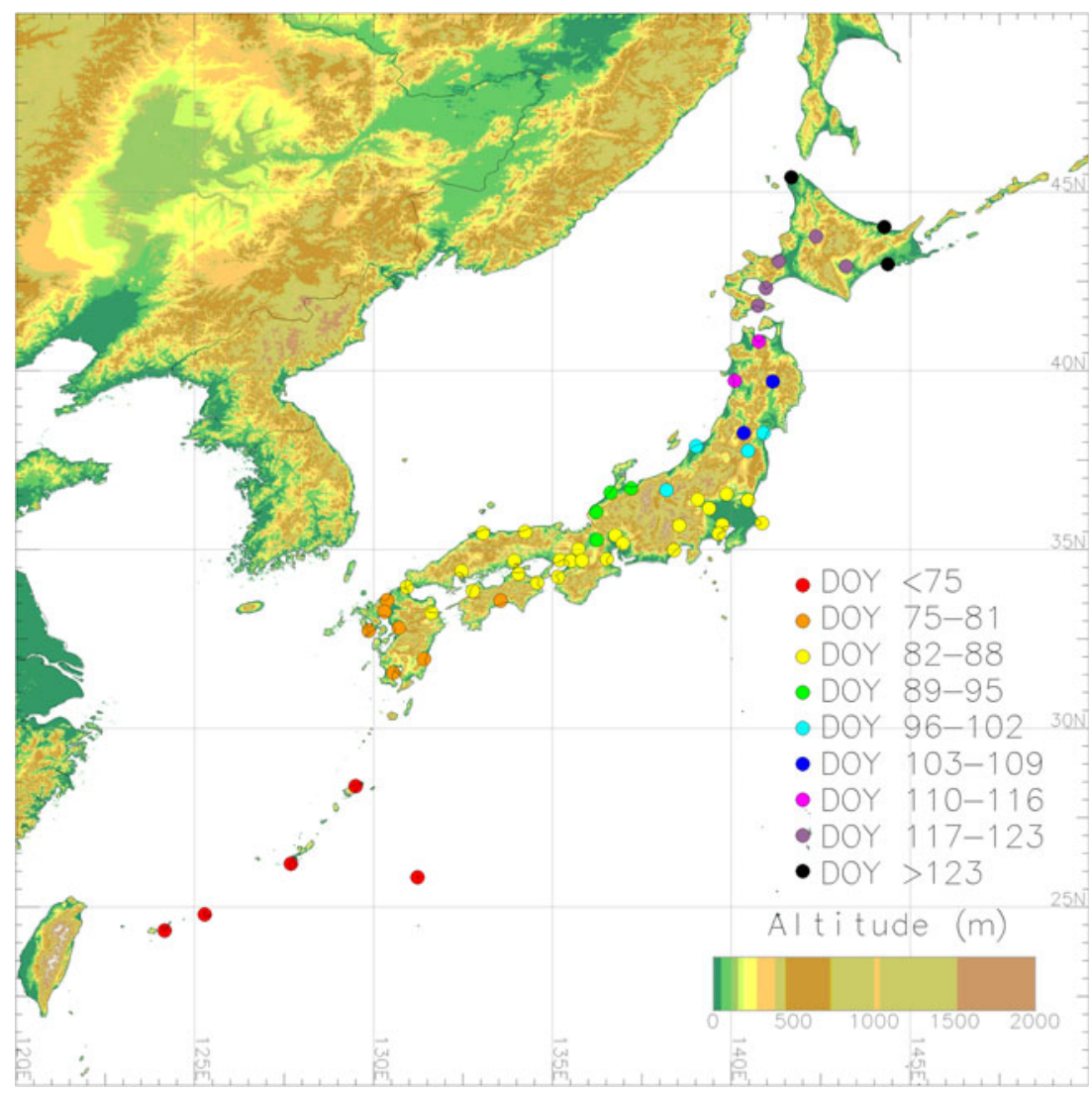

coniferous forest (Japanese cedar, Cryptomeria japonica) and an Alaskan open canopy evergreen coniferous forest (black spruce, Picea mariana). However, insufficient comparative studies have been conducted in Japan.

Sonnentag et al. (2012) compared the RGB-derived indices extracted from images taken from several types of digital cameras. They found that the seasonal patterns of RGB-derived indices were likely to be more relevant to detecting changes in plant phenology than were particular RGB-derived indices values. This means that the seasonal patterns of the changes in RGB-derived indices could be used to detect phenological transitions without having to account for the characteristics of different types of digital cameras. However, additional examinations of the unique and common characteristics of the seasonal variation of RGB-derived indices are required for Japan and elsewhere.

Very steep terrain, with large altitude changes (e.g., $900 \mathrm{~m}$ ) over short distances (e.g., $14 \mathrm{~km}$ ), exists in the mountainous region of central Japan (Muraoka and Koizumi 2009). Nagai et al. (2015b) reported that along a vertical gradient in deciduous forests between $35^{\circ} \mathrm{N}$ and $46^{\circ} \mathrm{N}$, leaf flush began 1 day later per 38.6 to $68.5 \mathrm{~m}$ increase in altitude and leaf fall began 1 day earlier per 78.1 to $142.9 \mathrm{~m}$ increase. This suggests the possibility that studying a small river basin in steep terrain would let researchers evaluate the sensitivity of plant phenology to climate change using a "space for time substitution," although more such studies are needed to confirm this. Studies conducted over a wide range of latitudes (horizontal distance) are also required to account for the spatial distribution of tree species and populations, genetic diversity, and phenological plasticity (Doi et al. 2010). However, studies over a wide range of latitudes include more uncertainties because of the greater variation in topographic and environmental characteristics.

In forest ecosystems, digital cameras have generally been installed at the top of $\mathrm{CO}_{2}$ flux or ecosystem observation towers (Richardson et al. 2007; Nasahara and Nagai 2015). Nagai et al. (2013b) found that the seasonal patterns of RGBderived indices extracted from upward images taken from the forest floor detected canopy phenology almost as well as downward images taken from the top of a tower in a closed canopy deciduous broad-leaved forest. Eliminating the requirement to install towers would allow such studies to be conducted at more sites for the same research budget.

Plant phenology is mainly affected by physiological events such as the onset of flowering or changes of leaf biomass and the amount of leaf pigments (Sims and Gamon 2002); Nagai et al. (2011a) found that RGB-derived indices can sensitively detect these changes based on changes of leaf color during leaf flush (from yellowish to dark green) and leaf coloring (from yellowish green to yellow or red). This seasonal variation can also be detected by spectral reflectance data and vegetation indices measured by spectral radiometers. In particular, the 
Table 1 Summary of the first flowering date (day of year, DOY) of cherry (Prunus $\times$ yedoensis; somei-yoshino) near 58 weather stations based on data published on the Web site of the Japan Meteorological Agency

\begin{tabular}{|c|c|c|c|c|c|c|c|c|c|c|c|}
\hline \multirow[t]{2}{*}{ Site name } & \multirow{2}{*}{$\begin{array}{l}\text { Latitude } \\
\left({ }^{\circ} \mathrm{N}\right)\end{array}$} & \multirow{2}{*}{$\begin{array}{l}\text { Longitude } \\
\left({ }^{\circ} \mathrm{E}\right)\end{array}$} & \multirow{2}{*}{$\begin{array}{l}\text { Annual mean air } \\
\text { temperature }\left({ }^{\circ}\right)^{\mathrm{a}}\end{array}$} & \multirow{2}{*}{ 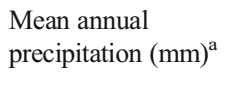 } & \multicolumn{6}{|l|}{ DOY } & \multirow[t]{2}{*}{ Substitute species } \\
\hline & & & & & 2011 & 2012 & 2013 & 2014 & 2015 & Normal $^{\mathrm{a}}$ & \\
\hline Wakkanai & 45.4150 & 141.6783 & 6.8 & 1062.8 & 139 & 135 & 146 & 131 & 123 & 134 & Prunus sargentii \\
\hline Asahikawa & 43.7567 & 142.3717 & 6.8 & 1042.1 & 129 & 123 & 138 & 122 & 117 & 125 & Prunus sargentii \\
\hline Abashiri & 44.0167 & 144.2783 & 6.5 & 787.5 & 136 & 124 & 145 & 127 & 120 & 131 & Prunus sargentii \\
\hline Sapporo & 43.0600 & 141.3283 & 8.9 & 1106.6 & 127 & 122 & 133 & 119 & 112 & 123 & \\
\hline Obihiro & 42.9217 & 143.2117 & 6.8 & 887.8 & 123 & 126 & 130 & 117 & 116 & 124 & Prunus sargentii \\
\hline Kushiro & 42.9850 & 144.3767 & 6.2 & 1042.9 & 138 & 138 & 143 & 132 & 126 & 137 & Prunus sargentii \\
\hline Muroran & 42.3117 & 140.9750 & 8.6 & 1184.9 & 126 & 130 & 136 & 119 & 118 & 126 & \\
\hline Hakodate & 41.8167 & 140.7533 & 9.1 & 1151.9 & 122 & 123 & 128 & 118 & 111 & 120 & \\
\hline Aomori & 40.8217 & 140.7683 & 10.4 & 1300.2 & 115 & 120 & 119 & 112 & 104 & 114 & \\
\hline Akita & 39.7167 & 140.0983 & 11.7 & 1686.6 & 113 & 115 & 113 & 110 & 101 & 108 & \\
\hline Morioka & 39.6983 & 141.1650 & 10.2 & 1266.2 & 110 & 115 & 113 & 103 & 99 & 111 & \\
\hline Yamagata & 38.2550 & 140.3450 & 11.7 & 1163.2 & 108 & 114 & 105 & 104 & 100 & 105 & \\
\hline Sendai & 38.2617 & 140.8967 & 12.4 & 1254.2 & 102 & 109 & 99 & 97 & 93 & 101 & \\
\hline Fukushima & 37.7583 & 140.4700 & 13.0 & 1166.1 & 102 & 107 & 95 & 98 & 92 & 99 & \\
\hline Nigata & 37.8933 & 139.0183 & 13.9 & 1821.0 & 104 & 107 & 97 & 97 & 92 & 99 & \\
\hline Kanazawa & 36.5883 & 136.6333 & 14.6 & 2398.9 & 97 & 101 & 89 & 91 & 90 & 94 & \\
\hline Toyama & 36.7083 & 137.2017 & 14.1 & 2300.1 & 98 & 103 & 88 & 92 & 91 & 95 & \\
\hline Nagano & 36.6617 & 138.1917 & 11.9 & 932.7 & 105 & 109 & 96 & 101 & 94 & 103 & \\
\hline Utsunomiya & 36.5483 & 139.8683 & 13.8 & 1493.1 & 96 & 99 & 80 & 88 & 89 & 91 & \\
\hline Fukui & 36.0550 & 136.2217 & 14.5 & 2237.7 & 97 & 101 & 87 & 90 & 90 & 93 & \\
\hline Maebashi & 36.4050 & 139.0600 & 14.6 & 1248.5 & 93 & 99 & 81 & 88 & 87 & 90 & \\
\hline Kumagaya & 36.1500 & 139.3800 & 15.0 & 1286.4 & 91 & 95 & 78 & 87 & 86 & 88 & \\
\hline Mito & 36.3800 & 140.4667 & 13.6 & 1353.8 & 96 & 97 & 80 & 88 & 89 & 92 & \\
\hline Gifu & 35.4000 & 136.7617 & 15.8 & 1827.6 & 87 & 90 & 80 & 83 & 82 & 85 & \\
\hline Nagoya & 35.1667 & 136.9650 & 15.8 & 1535.4 & 86 & 90 & 78 & 83 & 80 & 85 & \\
\hline Kofu & 35.6667 & 138.5533 & 14.7 & 1135.3 & 88 & 92 & 78 & 87 & 84 & 86 & \\
\hline Chōshi & 35.7383 & 140.8567 & 15.4 & 1660.0 & 94 & 93 & 80 & 88 & 89 & 90 & \\
\hline Tsu & 34.7333 & 136.5183 & 15.9 & 1581.3 & 91 & 95 & 84 & 86 & 88 & 89 & \\
\hline Shizuoka & 34.9750 & 138.4033 & 16.6 & 2325.0 & 79 & 84 & 76 & 83 & 81 & 84 & \\
\hline Tokyo & 35.6917 & 139.7500 & 15.4 & 1528.8 & 87 & 91 & 75 & 84 & 82 & 85 & \\
\hline Yokohama & 35.4383 & 139.6517 & 15.8 & 1688.8 & 89 & 93 & 77 & 84 & 82 & 85 & \\
\hline Matsue & 35.4567 & 133.0650 & 14.9 & 1787.2 & 96 & 97 & 82 & 86 & 88 & 90 & \\
\hline Tottori & 35.4867 & 134.2383 & 14.9 & 1914.0 & 92 & 94 & 79 & 86 & 87 & 90 & \\
\hline Kyoto & 35.0133 & 135.7317 & 15.9 & 1491.3 & 87 & 94 & 81 & 86 & 86 & 87 & \\
\hline Hikone & 35.2750 & 136.2433 & 14.7 & 1570.9 & 91 & 99 & 89 & 92 & 90 & 92 & \\
\hline Hiroshima & 34.3983 & 132.4617 & 16.3 & 1537.6 & 91 & 93 & 81 & 84 & 83 & 86 & \\
\hline Okayama & 34.6850 & 133.9250 & 16.2 & 1106.2 & 90 & 94 & 83 & 87 & 87 & 88 & \\
\hline Kobe & 34.6967 & 135.2117 & 16.7 & 1216.3 & 90 & 93 & 80 & 86 & 86 & 87 & \\
\hline Osaka & 34.6817 & 135.5183 & 16.9 & 1279.1 & 90 & 93 & 80 & 86 & 85 & 87 & \\
\hline Wakayama & 34.2283 & 135.1633 & 16.6 & 1317.0 & 86 & 90 & 77 & 85 & 82 & 85 & \\
\hline Nara & 34.6933 & 135.8267 & 14.9 & 1316.1 & 90 & 94 & 81 & 86 & 86 & 88 & \\
\hline Matsuyama & 33.8433 & 132.7767 & 16.5 & 1314.9 & 84 & 90 & 76 & 83 & 86 & 84 & \\
\hline Takamatsu & 34.3167 & 134.0533 & 16.3 & 1082.4 & 90 & 93 & 81 & 85 & 83 & 87 & \\
\hline Kochi & 33.5667 & 133.5483 & 16.9 & 2547.6 & 81 & 81 & 74 & 77 & 81 & 81 & \\
\hline Tokushima & 34.0667 & 134.5733 & 16.6 & 1453.9 & 90 & 92 & 83 & 88 & 87 & 87 & \\
\hline Shimonoseki & 33.9483 & 130.9250 & 16.7 & 1684.5 & 89 & 90 & 78 & 84 & 84 & 86 & \\
\hline Fukuoka & 33.5817 & 130.3750 & 17.0 & 1612.5 & 81 & 87 & 72 & 78 & 81 & 82 & \\
\hline Saga & 33.2650 & 130.3050 & 16.5 & 1870.2 & 81 & 88 & 77 & 78 & 81 & 83 & \\
\hline
\end{tabular}


Table 1 (continued)

\begin{tabular}{|c|c|c|c|c|c|c|c|c|c|c|c|}
\hline \multirow[t]{2}{*}{ Site name } & \multirow{2}{*}{$\begin{array}{l}\text { Latitude } \\
\left({ }^{\circ} \mathrm{N}\right)\end{array}$} & \multirow{2}{*}{$\begin{array}{l}\text { Longitude } \\
\left({ }^{\circ} \mathrm{E}\right)\end{array}$} & \multirow{2}{*}{$\begin{array}{l}\text { Annual mean air } \\
\text { temperature }\left({ }^{\circ}\right)^{\mathrm{a}}\end{array}$} & \multirow{2}{*}{$\begin{array}{l}\text { Mean annual } \\
\text { precipitation }(\mathrm{mm})^{\mathrm{a}}\end{array}$} & \multicolumn{6}{|l|}{ DOY } & \multirow[t]{2}{*}{ Substitute species } \\
\hline & & & & & 2011 & 2012 & 2013 & 2014 & 2015 & Normal $^{\mathrm{a}}$ & \\
\hline Oita & 33.2350 & 131.6183 & 16.4 & 1644.7 & 82 & 87 & 73 & 84 & 85 & 83 & \\
\hline Nagasaki & 32.7333 & 129.8667 & 17.2 & 1857.7 & 82 & 86 & 75 & 79 & 81 & 83 & \\
\hline Kumamoto & 32.8133 & 130.7067 & 16.9 & 1985.9 & 80 & 85 & 75 & 79 & 80 & 82 & \\
\hline Kagoshima & 31.5550 & 130.5467 & 18.6 & 2265.7 & 82 & 86 & 74 & 79 & 80 & 85 & \\
\hline Miyazaki & 31.9383 & 131.4133 & 17.4 & 2508.7 & 82 & 84 & 72 & 78 & 81 & 83 & \\
\hline Naze & 28.3783 & 129.4950 & 21.7 & 2837.7 & 30 & 20 & 14 & 16 & 20 & 19 & Prunus campanulata \\
\hline Ishigaki-jima & 24.3367 & 124.1633 & 24.3 & 2106.8 & 17 & $359^{\mathrm{b}}$ & 22 & 16 & 6 & 16 & Prunus campanulata \\
\hline Miyako-jima & 24.7933 & 125.2783 & 23.6 & 2021.1 & 17 & 18 & 19 & 16 & 22 & 16 & Prunus campanulata \\
\hline Naha & 26.2067 & 127.6867 & 23.0 & 2040.9 & 7 & 22 & $362^{\mathrm{b}}$ & 15 & 15 & 18 & Prunus campanulata \\
\hline Minami-Daito-jima & 25.8283 & 131.2283 & 23.3 & 1591.6 & 24 & 17 & 7 & 7 & 15 & 20 & Prunus campanulata \\
\hline
\end{tabular}

The data in this table was obtained from the biometeorological and meteorological observations conducted by the Japan Meteorological Agency (http:// www.data.jma.go.jp/sakura/data/sakura003_06.html and http://www.jma.go.jp/jma/menu/menureport.html; in Japanese. Accessed 12 August 2015)

${ }^{\text {a }}$ Average from 1981 to 2010

${ }^{\mathrm{b}}$ Observed in the preceding year

green-red vegetation index (GRVI), which is based on the visible red and green reflectance bands, was better able to detect the canopy surface color changes than the normalizeddifference vegetation index (NDVI) and the enhanced vegetation index (EVI), which are based on the visible red and blue and near-infrared reflectance bands (Motohka et al. 2010; Ide and Oguma 2011; Nagai et al. 2014a).
However, automatic fixed-point observations that target the whole canopy using spectral radiometers cannot detect differences in the seasonal changes among tree species. Nakaji et al. (2011) found that the seasonal variation in phenology of each deciduous broad-leaved tree species could be detected by measurements with a three-band multispectral camera. Saitoh et al. (2012) found that the seasonal variation in whole canopy
Fig. 2 Summary of the locations of the sites in each phenological observation network discussed in the text. The locations of the sites were determined by using Google Maps (http://maps.google.com/. Accessed 12 August 2015), information from each network's Web site (INIS, http://www. sizenken.biodic.go.jp. Accessed 12 August 2015; PEN, http:// www.pheno-eye.org. Accessed 12 August 2015; Cyberforest, http://landscape.nenv.k.u-tokyo. ac.jp/cyberforest/Welcome.html. Accessed 12 August 2015), and the literature (Ueta et al. 2012). INIS Internet Nature Information System, PEN Phenological Eyes Network

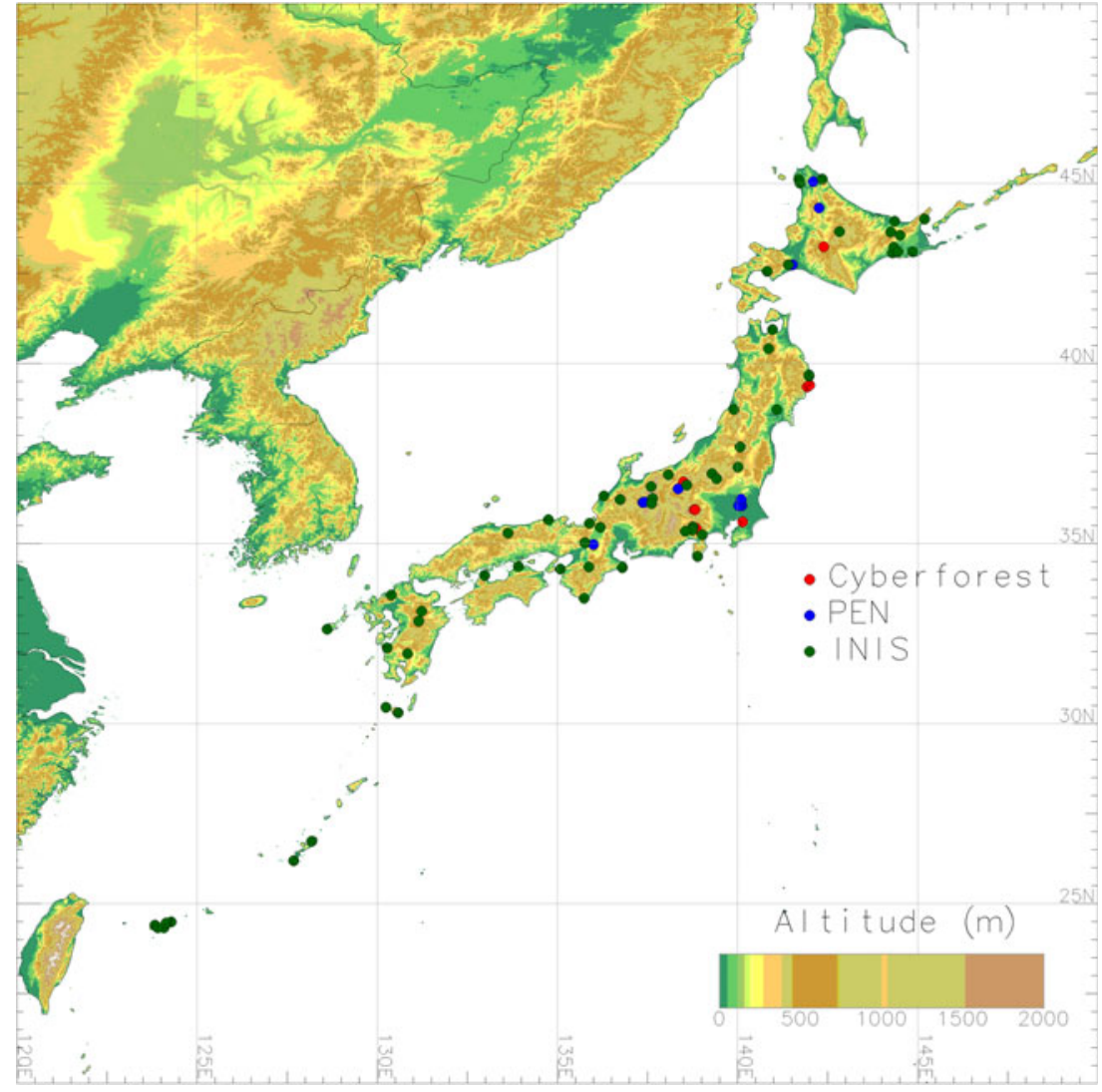


Table 2 Summary of Japanese studies that analyzed RGB values obtained from phenological images

\begin{tabular}{|c|c|c|c|c|}
\hline Ecosystem type & $\begin{array}{l}\text { Phenological } \\
\text { network }\end{array}$ & $\begin{array}{l}\text { Scale of image } \\
\text { target }(\mathrm{m})\end{array}$ & Camera direction & References \\
\hline Deciduous broad-leaved forest & PEN, INIS & 0.5 to 1000 & $\begin{array}{l}\text { Downward from towers; sideways from } \\
\text { buildings; upward from the ground }\end{array}$ & $\begin{array}{l}\text { Ide and Oguma (2010); Nagai et al. (2011a, } \\
\text { 2013a, 2013b, 2014b); Inoue et al. (2014) }\end{array}$ \\
\hline Deciduous coniferous forest & PEN & 20 to 200 & Downward from towers & Ide et al. (2011) \\
\hline Evergreen broad-leaved forest & INIS & 1000 & Sideways from buildings & Ide and Oguma (2010) \\
\hline Evergreen coniferous forest & PEN & 20 & $\begin{array}{l}\text { Downward from tower; upward } \\
\text { from the ground }\end{array}$ & Nagai et al. (2013a) \\
\hline Mixed forests & PEN & 20 & Sideways from building & Mizunuma et al. (2011) \\
\hline Grassland & PEN & 20 & Downward from tower & Akitsu et al. (2011) \\
\hline Wetland & INIS & 200 & Sideways from buildings & Ide and Oguma (2010) \\
\hline
\end{tabular}

PEN Phenological Eyes Network (Nasahara and Nagai 2015), INIS Internet Nature Information System (http://www.sizenken.biodic.go.jp. Accessed 12 August 2015)

RGB-derived indices was well correlated with that of spectral reflectance and the associated vegetation indices in deciduous broad-leaved and evergreen coniferous (Japanese cedar) forests. This suggests that RGB-derived indices for each tree or species may be a proxy for spectral reflectance values and vegetation indices (Ide and Oguma 2011). Noda et al. (2015a) measured the spectral reflectance values of various deciduous and evergreen tree species at the scale of individual leaves. However, it would be prohibitively difficult to perform such observations for multiple tree species and individuals at multiple points because of the high cost of the instruments and the labor-intensive analysis. Further examinations of the relationship between RGB-derived indices and spectral characteristics for a range of tree species will be required to confirm that RGB-derived indices can be used as proxies for spectral reflectance and vegetation indices. In addition, examination of the relationships between seasonal variation of RGB-derived indices, leaf traits, and ecophysiological parameters for various tree species (Noda et al. 2015b) would provide useful direct evidence for analysis of GPP values (Ide and Oguma 2011).

Digital cameras can capture phenological observations at shoot, canopy, and landscape scales. However, the long distance between the camera and the target vegetation that is required to cover larger areas may prevent detailed phenological observations. Nagai et al. (2014b) found that the year-to-year variation in the timing of full blooming of Prunus sargentii could be detected at a canopy scale, but detailed continuous flowering phenology could not. Inoue et al. (2014) reported that the threshold RGB-derived index values for detection of the timing of leaf flush and leaf fall could not be defined uniquely by analyzing phenological images taken with a fisheye lens. The problem resulted from the different conditions of target individuals; the center of the images captured the canopy surface of a tree, whereas the perimeter captured the side of the canopy. These results suggest that it may be necessary to install multiple digital cameras at a study site to capture enough usable images at different spatial scales. In addition, the problem resulted from a requirement to identify particular RGB-derived index values (i.e., thresholds) for determining phenological transitions. Curve fitting approaches that can detect the inflection point for RGB-derived indices during a phenological change may help to solve this problem (Ide and Oguma 2013; Henneken et al. 2014; Klosterman et al. 2014). To continuously observe detailed flowering, fruiting, leaf flush, leaf coloring, and leaf fall phenology, it will be necessary to improve phenological observations at the shoot scale, as has been done by Cyberforest (Saito et al. 2004), and comparative analyses of phenological images acquired at different spatial scales will be required.

To conserve biodiversity, the Japanese government developed and revised the national biodiversity strategy in 2012 (MEJ 2012). This strategy has actively encouraged learning by students through hands-on experience with environmental studies. Such learning is now included in the course of study developed by Japan's Ministry of Education, Culture, Sports, Science and Technology (http://www.mext.go.jp). For instance, phenological observations of plants such as morning glory (Ipomoea spp.) are a valued part of science education at Japanese primary schools. To encourage learning through environmental studies, the online phenological data published on the Web site of Cyberforest may be helpful. Phenological observations by digital cameras are also helpful because they can replace or complement labor-intensive phenological observations using index trees conducted in university research forests and exhibition gardens (Fujimoto 2007; Sato 2014; the tree phenological observation network conducted by the Research Forests Council of Japanese universities, http://www.forest.kyushu-u.ac.jp/phenology/. Accessed 12 August 2015). Ide and Oguma (2013) demonstrated the usefulness of phenological observations by digital cameras in alpine ecosystems, where accessibility is difficult but remarkable environmental changes are occurring (Kudo 2014). These phenological observations by digital cameras may encourage 
students to pursue their interests through both university education and lifelong environmental learning. Strengthening cooperation with citizen scientists in a project such as the "Monitoring Sites 1000 Project," conducted by the Ministry of the Environment's Biodiversity Center of Japan (Kudo 2014; http://www.biodic.go.jp/moni1000/. Accessed 12 August 2015), may also develop environmental studies by encouraging activities related to phenological observation networks implemented using digital cameras.

\section{Spectral radiometers}

Spectral reflectance and vegetation indices measured by fixedpoint spectral radiometers can detect the characteristics of plant phenology in secondary deciduous broad-leaved forest (Motohka et al. 2010; Nagai et al. 2010a), deciduous coniferous larch forest (Motohka et al. 2010), evergreen coniferous cypress (Chamaecyparis obtusa) forest (Nakaji et al. 2008) and Japanese cedar forest (Nagai et al. 2012), and grassland (Motohka et al. 2010). However, fewer ecosystems and study sites have been used for measurements with fixed-point spectral radiometers than for fixed-point digital cameras. Nasahara and Nagai (2015) used spectral radiometers to detect the mean tree phenology within 2 to $10 \mathrm{~m}$ of the device. To support ground truthing for satellite remote-sensing data is problematic because the footprint of the in situ spectral measurement is much smaller than that of the satellite data (typically $\geq 30 \mathrm{~m}$ and as great as $1000 \mathrm{~m}$ ).

NDVI, EVI, and GRVI values in deciduous forests and grasslands increase rapidly during leaf flush and then become saturated before the vegetation achieves its maximum leaf area; they then decrease gradually during the leaf coloring and leaf fall periods (Nagai et al. 2010a; Motohka et al. 2010). Nagai et al. (2010a) examined the relationship between NDVI and EVI values observed by a spectral radiometer and the corresponding phenological images in a deciduous broad-leaved forest. NDVI values of 0.6 to 0.7 and EVI values of 0.4 to 0.5 potentially detected the onset of leaf flush, but neither index could detect the timing of leaf fall. This problem resulted from differences in the characteristics of the pattern and timing of leaf coloring and leaf fall among tree species (Nagai et al. 2014a). Nagai et al. (2014a) examined the relationship between seasonal variation of spectral reflectance and vegetation indices and spatial and temporal variations of leaf litter in a deciduous broad-leaved forest. GRVI, which observes only the seasonal color variation of the canopy surface, detected the timing of leaf fall more accurately than NDVI and EVI. Motohka et al. (2010) examined the relationship between seasonal variation of spectral reflectance and vegetation indices and daily phenological images in several deciduous forests and a grassland. The first date on which GRVI was greater than zero in the spring and the first date on which GRVI was less than zero in the autumn corresponded to the start and end of the growing season, respectively. This ground truthing information indicated a general ability to detect the start and end of the growing season in deciduous forests and a grassland by thresholdbased analysis using GRVI (Motohka et al. 2010).

The seasonality of NDVI and EVI in evergreen coniferous forests was much smaller than that in deciduous forests (Nakaji et al. 2008; Nagai et al. 2012). In contrast, GRVI could detect the seasonal variation of leaf coloring at the canopy surface of a Japanese cedar forest in winter (winter reddening; Nagai et al. 2012). The seasonal variation of leaf color at the canopy surface in Japanese cedar forests was caused by changes in leaf pigments (Han et al. 2003). This seasonality correlated well with the seasonal variation in leaf photosynthetic capacity (Nagai et al. 2012). Detecting such changes is important because evergreen coniferous forests account for $30 \%$ of Japan's total forested area (Japan FAO Association 1997).

Many previous studies indicated that seasonal variation of satellite EVI values was correlated with that of GPP in various ecosystems (Rahman et al. 2005; Huete et al. 2006). These reports suggest that GPP could be directly evaluated by satellite EVI. To test this possibility, Nagai et al. (2010b) and Muraoka et al. (2013) examined the relationships between EVI values observed with a spectral radiometer and GPP obtained from $\mathrm{CO}_{2}$ flux tower measurements and between various vegetation indices (including EVI) observed with a spectral radiometer and photosynthetic capacity estimated by ecophysiological measurements and ecosystem modeling in the same deciduous broad-leaved forest. GPP increased exponentially with increasing EVI in spring; in contrast, GPP showed a linear decrease with decreasing EVI in autumn.

Previous studies used 8-, 10-, and 16-day composite satellite EVI data that comprised the best-quality data, with no effects of cloud contamination or atmospheric noise within these periods (Rahman et al. 2005; Huete et al. 2006). Estimated GPP values based on the composite satellite data were closer to the potential GPP values (i.e., the GPP under ideal conditions) observed under clear skies than to estimates of the actual GPP values under clear skies or rainy and cloudy conditions (Nagai et al. 2010b). During the leaf flush and leaf fall periods, high-quality Terra/MODIS NDVI data with no effects of cloud contamination or atmospheric noise were available in Japan for only 3 to 7 days per month (Nagai et al. 2011b). For this reason, GPP values estimated from satellite Japanese EVI data may overestimate the real values.

\section{Phenological observations by satellite remote sensing}

In this section, we will briefly summarize previous phenological research based on satellite remote sensing. Our previous research found fewer phenological studies in Japan than in 
North America, Europe, and mainland Asia (Nagai et al. 2015b). This may be because the 8-km spatial resolution of the Global Inventory Modeling and Mapping Studies data (http://staff.glcf.umd.edu/sns/branch/htdocs.sns/data/gimms/. Accessed 12 August 2015) is too coarse to account for the heterogeneous Japanese plant phenology that results from the complex topography and vegetation cover. In contrast, the Terra and Aqua/MODIS GRVI, with 500-m spatial resolution, could detect the spatial variation in the timing of the start and end of the growing season along both vertical and horizontal gradients in Japan (Nagai et al. 2015b). Figure 3 shows the resulting spatial distribution of the timing of the start and end of the growing season in 2014.

To accurately evaluate the sensitivity of plant phenology to climate change, it is necessary to evaluate the year-to-year spatial variation of the timing of leaf flush and leaf fall over a wide area and a long time period. Although Nagai et al. (2015b) performed a decadal-scale analysis for Japan, they only showed the mean spatial and temporal timing of the start and end of the growing season during the study period for horizontal zones $\left(2^{\circ}\right.$ latitude intervals) and vertical zones (200-m intervals). Previous research suggests that in a temperate climate, the sensitivity of plant phenology to climate change is clearer in southern parts of the region than in northern parts (Shen et al. 2014; Wang et al. 2015). In Japan, many river basins are divided by mountain ranges, creating small climatic zones close to each other but with different geographical characteristics. These divisions often occur at the boundaries between local authorities that are responsible for

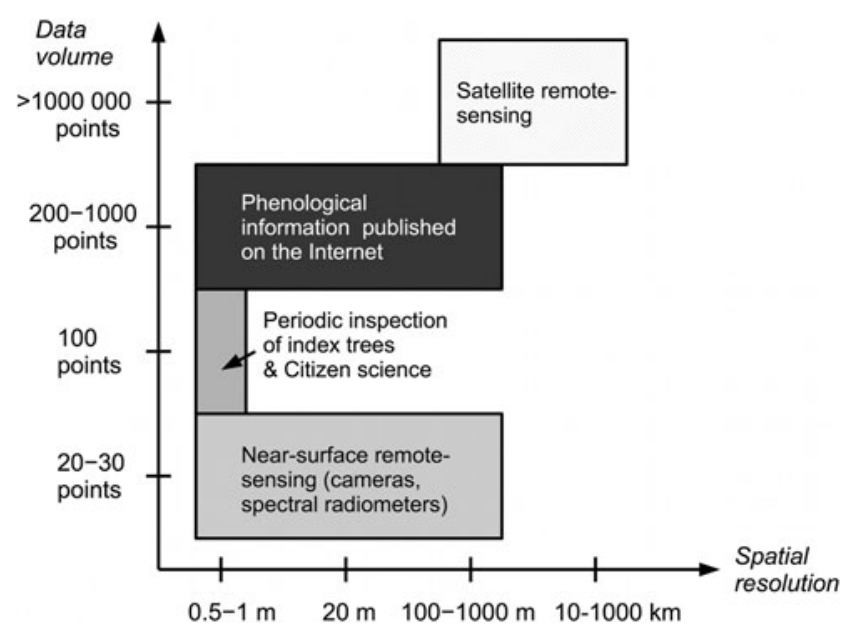

Fig. 4 Summary of the relationship between the amount and spatial resolution of the available datasets for phenological observations. Data obtained by citizen scientists tends to be openly published on the Internet

tracking phenological data. As a result, obtaining a detailed evaluation of the sensitivity of plant phenology to climate change would require the participation of Japan's 47 prefectural and city governments.

Hadano et al. (2013) calibrated a phenological model for prediction of the timing of leaf flush by using both spatial variation of this timing detected from MODIS GRVI data with a 500-m spatial resolution and meteorological data at weather stations throughout Japan. They predicted the spatial and temporal variation of the timing of leaf flush under future climate change. Previous phenological models were based on in situ

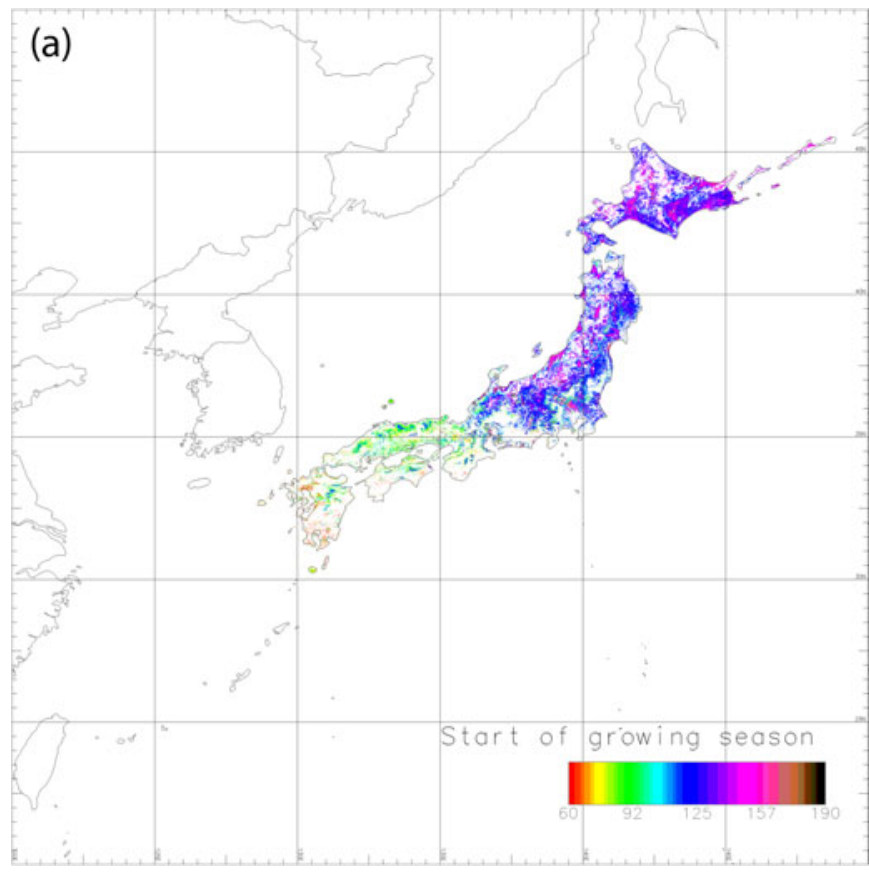

Fig. 3 Spatial distribution of $\mathbf{a}$ the start and $\mathbf{b}$ the end of the growing season (day of year) in 2014, detected by analyzing the daily Terra and Aqua MODIS GRVI observations with 500-m spatial resolution. White

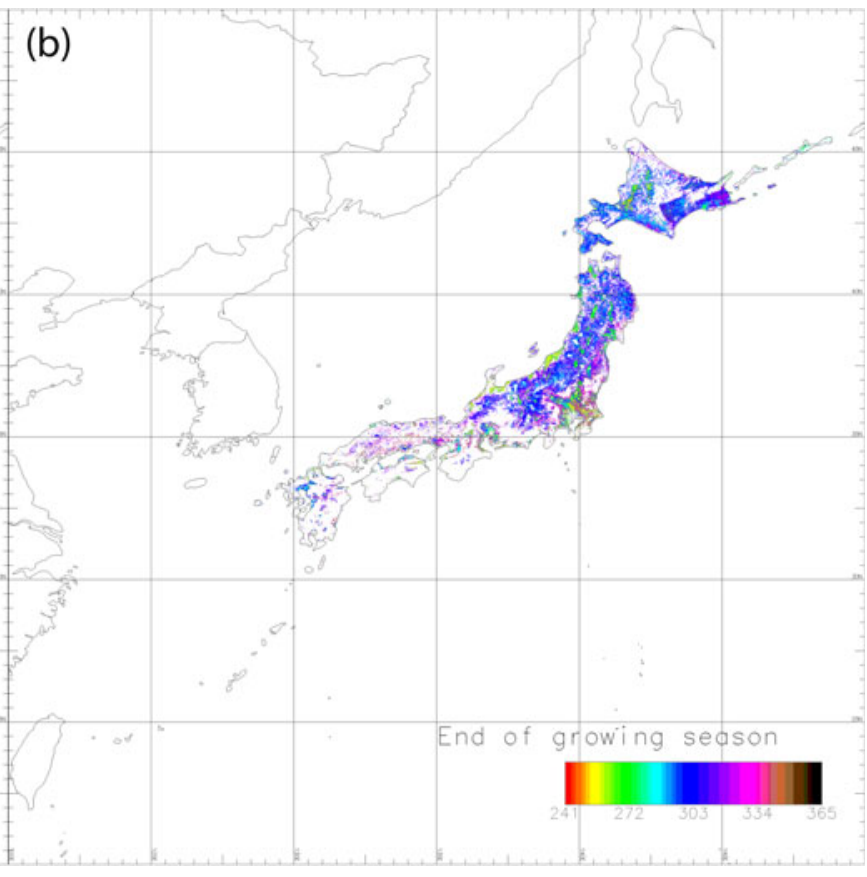

shows evergreen forests or points where we could not evaluate the timing of start or end of the growing season. For details of the method, see Nagai et al. (2015b) 
phenological datasets at multiple points (Xu and Chen 2013), and Hadano et al. (2013) suggested that it may be possible to accurately detect the sensitivity of plant phenology to climate change by integrating an analysis of satellite data with such a phenological model. In a temperate zone, the timing of flowering and leaf flush was estimated based on the number of chilling hours in winter and on the number of warming hours before bud burst in spring (Kim et al. 2012; Luedeling et al. 2013). Examining the relationship between the spatial variation of the timing of flowering and leaf flush predicted by phenological models and the timing of leaf flush detected by satellite observations may improve our understanding of the sensitivity of plant phenology to climate change at regional to continental scales.

Nagai et al. (2015a) examined the relationship between the spatial variation of Landsat- 8 GRVI values with a $30-\mathrm{m}$ spatial resolution and leaf coloring information published on Web sites on 1 day during the leaf coloring period in 2014. Ground truthing information for plant phenology obtained from weather stations, research forests, agricultural experiment stations, and phenological observation sites with digital cameras is not sufficient because of the scale mismatch between the satellite and in situ data. Further examination of the relationship between satellite-detected plant phenology and phenological information published on the Internet is required to account for the footprint of the satellite data.

Sekizawa et al. (2015) detected the evacuation-induced land cover changes following the Fukushima Daiichi nuclear power plant disaster in 2011 by analyzing seasonal patterns of vegetation indices derived from MODIS data with a 250-m spatial resolution. Plant phenology may change significantly in response to changes in land cover or land use, ecological succession, and invasion by nonnative species. In Japan, progressive abandonment of cultivation and succession to bamboo forests has occurred in mid- to low-elevation mountains and suburban regions (MEJ 2012). Further studies will be required to accurately evaluate the relationship between the spatial and temporal variability of satellite-observed vegetation indices and those of vegetation cover at scales ranging from individual sites to whole landscapes.

\section{Conclusions and future developments}

In the many previous studies described in this review, phenological observations were obtained using index trees for a few tree species, near-surface remote-sensing observations for a few ecosystems or tree species, and satellite remote sensing at a regional scale. The differences in these approaches resulted from the different goals of the studies and differences in the available data. Suzuki (2015) noted that many previous studies of remote-sensing data were mainly from a technical perspective and that the ecological meaning 
of the signals was not sufficiently considered. In addition, many previous studies only used the limited datasets observed by scientists and other experts rather than the larger amount of data provided by citizen scientists. This may have prevented researchers from obtaining phenological data at a synoptic scale that covered multiple species over wide areas.

To solve these problems, researchers should attempt a multidisciplinary analysis that links index trees, near-surface remote sensing, satellite remote sensing, citizen science, and open-access information published on the Internet. Figure 4 illustrates the relationship between the amounts and spatial resolutions of the available phenological datasets. Japanese citizens are very interested in plant phenology, and their interest provides data at a small personal scale that can be linked with the abundant data at wider regional and national scales. Establishing this link will require the development of databases of phenological observations that will reveal ecosystem changes from the leaf scale to national scales (Muraoka and Koizumi 2009). Each source of data has advantages and problems (Table 3), but because these differ among the data sources, the advantages of one dataset may compensate for another dataset's limitations.

Two studies from outside Japan provide examples of successful multidisciplinary studies that linked remote-sensing observations with index tree observations or citizen science. Delbart et al. (2015) examined the relationship between the start of the growing season in Canada, detected by SPOT/VEGETATION vegetation index data, and the timing of flowering and leaf flush reported by citizen scientists. The phenological information observed by the citizen scientists provided useful ground truthing for the satellite data. Kim et al. (2012) examined the relationships among the timing of cherry blooming at multiple locations in Korea, the start of the growing period detected from a MODIS vegetation index, and a model for prediction of the timing of leaf flush. Phenological information from index tree observations provided useful data for a multidisciplinary phenological study in both cases.

Phenological studies tend to be local because of the specific and diverse goals of the researchers. Unfortunately, this also means that there have been no direct comparisons between Japanese plant phenology and that in other countries. On the other hand, many Japanese studies were conducted both before and after World War II. However, those studies were published in Japanese. As a result, insufficient Japanese phenological information has been made available to the international research community (Ogawa-Onishi and Berry 2013). Recently, huge amounts of phenological information have become available on the Internet in Japanese, which means that it remains unavailable to researchers who cannot read Japanese. By way of example, Table 1 summarizes the first flowering date of cherry near 58 weather stations in Japan published by the Japan Meteorological Agency. To solve these issues, we propose the following challenging but important tasks: (1) We should conduct more multidisciplinary phenological studies in Japan through collaboration among researchers with different goals and between researchers and citizen scientists, with the aim of improving our understanding of phenology and permitting comparisons among observation networks. (2) We should evaluate both the unique characteristics of Japanese phenology and the characteristics shared with vegetation in other regions through international collaborations and through comparisons with results from foreign observation networks. (3) We should publicize Japanese language phenological data in the international research literature so that the data will be more accessible to the international research community. Of course, to accomplish this it will be necessary to obtain the necessary legal permissions to share this data, and it will also be necessary to find volunteers willing to translate the information into English and other languages. By implementing these recommendations, Japanese phenological studies will become increasingly powerful.

Acknowledgments We thank the editor and two anonymous reviewers for their kind and constructive comments. This study was supported by the Environment Research and Technology Development Fund (S-9) of the Ministry of the Environment of Japan.

\section{References}

Akitsu T, Nasahara KN, Noda H, Motohka T, Murakami K, Tsuchida S, Nagai S (2011) Long-term observation of seasonal and yearly variation of grassland by an automatic digital camera. Bulletin of the Terrestrial Environment Research Center, University of Tsukuba 12: $5-12$

Aono Y, Kazui K (2008) Phenological data series of cherry tree flowering in Kyoto, Japan, and its application to reconstruction of springtime temperatures since the 9th century. Int J Climatol 28:905-914

Aono Y, Tani A (2014) Autumn temperature deduced from historical records of autumn tints phenology of maple tree in Kyoto, Japan. Climate in Biosphere 14:18-28 (in Japanese with English abstract)

Buitenwerf R, Rose L, Higgins S.I. (2015) Three decades of multidimensional change in global leaf phenology. Nature Climate Change 5:DOI: 10.1038/NCLIMATE2533

Delbart N, Le Toan T, Kergoat L, Fedotova V (2006) Remote sensing of spring phenology in boreal regions: a free of snow-effect method using NOAA-AVHRR and SPOT-VGT data (1982-2004). Remote Sens Environ 101:52-62

Delbart N, Beaubien E, Kergoat L, Le Toan T (2015) Comparing land surface phenology with leafing and flowering observations from the PlantWatch citizen network. Remote Sens Environ 160:273-280

Doi H, Takahashi M (2008) Latitudinal patterns in the phenological responses of leaf colouring and leaf fall to climate change in Japan. Glob Ecol Biogeogr 17(4):556-561

Doi H, Takahashi M, Katano I (2010) Genetic diversity increases regional variation in phenological dates in response to climate change. Glob Chang Biol 16:373-379

Fujimoto S (2007) Analysis of prediction methods for budburst days based on the phenological observation in 29 broad-leaved tree species for 10 years. J Jpn For Soc 89:253-261(in Japanese with English abstract) 
Fujisawa M, Kobayashi K (2010) Apple (Malus pumila var. domestica) phenology is advancing due to rising air temperature in northern Japan. Glob Chang Biol 16:2651-2660

Hadano M, Nasahara KN, Motohka T, Noda HM, Murakami K, Hosaka M (2013) High-resolution prediction of leaf onset date in Japan in the 21st century under the IPCC A1B scenario. Ecol Evol 3:1798-1807

Han Q, Shinohara K, Kakubari Y, Mukai Y (2003) Photoprotective role of rhodoxanthin during cold acclimation in Cryptomeria japonica. Plant Cell Environ 26:715-723

Henneken R, Dose V, Schleip C, Menzel A (2014) Detecting plant seasonality from webcams using Bayesian multiple change point analysis. Agric For Meteorol 168:177-185

Huete AR, Didan K, Shimabukuro YE, Ratana P, Saleska SR, Hutyra LR, Yang W, Nemani RR, Myneni R (2006) Amazon rainforests greenup with sunlight in dry season. Geophys Res Lett 33:L06405. doi: 10.1029/2005GL025583

Ibáñez I, Primack RB, Miller-Rushing AJ, Ellwood E, Higuchi H, Lee SD, Kobori H, Silander JA (2010) Forecasting phenology under global warming. Phil Trans Royal Soc B 365:3247-3260

Ide R, Oguma H (2010) Use of digital cameras for phenological observations. Ecol Informat 5:339-347

Ide R, Oguma H (2013) A cost-effective monitoring method using digital time-lapse cameras for detecting temporal and spatial variations of snowmelt and vegetation phenology in alpine ecosystems. Ecol Informat 16:25-34

Ide R, Nakaji T, Motohka T, Oguma H (2011) Advantages of visible-band spectral remote sensing at both satellite and near-surface scales for monitoring the seasonal dynamics of GPP in a Japanese larch forest. J Agric Meteorol 67:75-84

Inoue T, Nagai S, Saitoh TM, Muraoka H, Nasahara KN, Koizumi H (2014) Detection of the different characteristics of year-to-year variation in foliage phenology among deciduous broad-leaved tree species by using daily continuous canopy surface images. Ecol Inform 22:58-68

Japan FAO Association (1997) Forests and forestry in Japan, 2nd ed. Japan FAO Association, Tokyo

JMA (1985) Guidelines for the observation of phenology, 3rd edn. Japan Meteorological Agency, Tokyo(in Japanese)

JMA (2014) Report on recent climatic change: Japan Meteorological Agency, Tokyo:253 pp(in Japanese)

Keenan TF, Gray J, Friedl MA, Toomey M, Bohrer G, Hollinger DY, Munger JW, O'Keefe J, Schmid HP, Wing IS, Yang B, Richardson AD (2014) Net carbon uptake has increased through warminginduced changes in temperate forest phenology. Nat Clim Chang 4:598-604

Kim S, Kang S, Lim J-H, Chun J-H, Sung J-H (2012) Regional parameterization of canopy onset models using MODIS and flowering onset data. Ecol Model 247:190-198

Klosterman ST, Hufkens K, Gray JM, Melaas E, Sonnentag O, Lavine I, Mitchell L, Norman R, Friedl MA, Richardson AD (2014) Evaluating remote sensing of deciduous forest phenology at multiple spatial scales using PhenoCam imagery. Biogeosciences 11: 4305-4320

Kudo G (2014) Vulnerability of phenological synchrony between plants and pollinators in an alpine ecosystem. Ecol Res 29:571-581

Linderholm HW (2006) Growing season changes in the last century. Agric For Meteorol 137:1-14

Luedeling E, Guo L, Dai J, Leslie C, Blanke MM (2013) Differential responses of trees to temperature variation during the chilling and forcing phases. Agric For Meteorol 181:33-42

Matsumoto K (2010) Causal factors for spatial variation in long-term phenological trends in Ginkgo biloba L. in Japan. Int J Climatol 30(9):1280-1288

Matsumoto K, Ohta T, Irasawa M, Nakamura T (2003) Climate change and extension of the Ginkgo biloba L. growing season in Japan. Glob Chang Biol 9:1634-1642
MEJ (2012) National Biodiversity Strategy of Japan 2012-2020. Ministry of the Environment of Japan, Tokyo, p. 252 pp(in Japanese)

Miller-Rushing AJ, Katsuki T, Primack RB, Ishii Y, Lee SD, Higuchi H (2007) Impact of global warming on a group of related species and their hybrids: cherry tree (Rosaceae) flowering at Mt. Takao, Japan. American J Botany 94:1470-1478

Mizunuma T, Koyanagi T, Mencuccini M, Nasahara KN, Wingate L, Grace J (2011) The comparison of several colour indices for the photographic recording of canopy phenology of Fagus crenata Blume in eastern Japan. Plant Ecol Divers 4:67-77

Morisette JT, Richardson AD, Knapp AK, Fisher JI, Graham EA, Abatzoglou J, Wilson BE, Breshears DD, Henebry GM, Hanes JM, et al. (2009) Tracking the rhythm of the seasons in the face of global change: phenological research in the 21st century. Frontiers Ecol Environ 7:253-260

Motohka T, Nasahara KN, Oguma H, Tsuchida S (2010) Applicability of green-red vegetation index for remote sensing of vegetation phenology. Remote Sens 2:2369-2387

Muraoka H, Koizumi H (2009) "Satellite Ecology" for linking ecology, remote sensing and micrometeorology from plot to regional scales for ecosystem structure and function study. J Plant Res 122:3-20

Muraoka H, Noda HM, Nagai S, Motohka T, Saitoh TM, Nasahara KN, Saigusa N (2013) Spectral vegetation indices as the indicator of canopy photosynthetic productivity in a deciduous broadleaf forest. J Plant Ecol 6:393-407

Nagai S, Inoue T, Ohtsuka T, Kobayashi H, Kurumado K, Muraoka H, Nasahara KN (2014a) Relationship between spatio-temporal characteristics of leaf-fall phenology and seasonal variations in near surface- and satellite-observed vegetation indices in a cooltemperate deciduous broad-leaved forest in Japan. Int J Remote Sens 35:3520-3536

Nagai S, Inoue T, Suzuki R (2015a) Leaf-coloring information published on web sites and its utility in the ground-truthing of satellite remotesensing data for mapping autumn leaf phenology. Jpn J Biometeorol 52(2):119-129(in Japanese with English abstract)

Nagai S, Maeda T, Muraoka H, Suzuki R, Nasahara KN (2011a) Using digital camera images to detect canopy condition of deciduous broad-leaved trees. Plant Ecol Divers 4:78-88

Nagai S, Nakai T, Saitoh TM, Busey RC, Kobayashi H, Suzuki R, Muraoka H, Kim Y (2013a) Seasonal changes in camera-based indices from an open canopy black spruce forest in Alaska, and comparison with indices from a closed canopy evergreen coniferous forest in Japan. Polar Sci 7:125-135

Nagai S, Nasahara KN, Muraoka H, Akiyama T, Tsuchida S (2010a) Field experiments to test the use of the normalized difference vegetation index for phenology detection. Agric For Meteorol 150:152-160

Nagai S, Saigusa N, Muraoka H, Nasahara KN (2010b) What makes the satellite-based EVI-GPP relationship unclear in a deciduous broadleaved forest? Ecol Res 25:359-365

Nagai S, Saitoh TM, Kobayashi H, Ishihara M, Motohka T, Suzuki R, Nasahara KN, Muraoka H (2012) In situ examination for the relationship between various vegetation indices and tree phenology in an evergreen coniferous forest, Japan. Int J Remote Sens 33: 6202-6214

Nagai S, Saitoh TM, Nasahara KN, Suzuki R (2015b) Spatio-temporal distribution of the timing of start and end of growing season along vertical and horizontal gradients in Japan. Int J Biometeorol 59: $47-54$

Nagai S, Saitoh TM, Noh NJ, Yoon TK, Kobayashi H, Suzuki R, Nasahara KN, Son Y, Muraoka H (2013b) Utility of information in photographs taken upwards from the floor of closed-canopy deciduous broadleaved and closed-canopy evergreen coniferous forests for continuous observation of canopy phenology. Ecol Inform 18:10-19 
Nagai S, Saitoh TM, Suzuki R, Nasahara KN, Lee W-K, Son Y, Muraoka $\mathrm{H}$ (2011b) The necessity and availability of noise-free daily satelliteobserved NDVI during rapid phenological changes in terrestrial ecosystems in East Asia. For Sci Tech 7:174-183

Nagai S, Yoshitake S, Inoue T, Suzuki R, Muraoka H, Nasahara KN, Saitoh TM (2014b) Year-to-year blooming phenology observation using time-lapse digital camera images. J Agric Meteorol 70(3):163-170

Nakaji T, Ide R, Takagi K, Kosugi Y, Ohkubo S, Nasahara KN, Saigusa $\mathrm{N}$, Oguma H (2008) Utility of spectral vegetation indices for estimation of light conversion efficiency in coniferous forests in Japan. Agric For Meteorol 148:776-787

Nakaji T, Oguma H, Hiura T (2011) Ground-based monitoring of the leaf phenology of deciduous broad-leaved trees using high resolution NDVI camera images. J Agric Meteorol 67(2):65-74

Nasahara KN, Nagai S (2015) Review: development of an in-situ observation network for terrestrial ecological remote sensing-the Phenological Eyes Network (PEN). Ecol Res 30(2):211-223

Natural Environmental Information GIS (1999) National surveys on the natural environment (5th survey on vegetation). Biodiversity Center of Japan (http://www.biodic.go.jp/index_e.html)

Noda HM, Motohka T, Murakami K, Muraoka H, Nasahara KN (2015a) Reflectance and transmittance spectra of leaves and shoots of 22 vascular plant species and reflectance spectra of trunks and branches of 12 tree species in Japan. Ecol Res doi:. doi:10.1007/s11284-013-1096-Z

Noda HM, Muraoka H, Nasahara KN, Saigusa N, Murayama S, Koizumi H (2015b) Phenology of leaf morphological, photosynthetic, and nitrogen use characteristics of canopy trees in a cool-temperate deciduous broadleaf forest at Takayama, central Japan. Ecol Res 30:247-266

Ogawa-Onishi Y, Berry PM (2013) Ecological impacts of climate change in Japan: the importance of integrating local and international publications. Biol Conserv 157:361-371

Ohashi Y, Kawakami H, Shigeta Y, Ikeda H, Yamamoto N (2012) The phenology of cherry blossom (Prunus yedoensis "Somei-yoshino") and the geographic features contributing to its flowering. Int J Biometeorol 56:903-914

Peñuelas J, Rutishauser T, Filella I (2009) Phenology feedbacks on climate change. Science 324:887-888

Polgar CA, Primack RB (2011) Leaf-out phenology of temperate woody plants: from trees to ecosystems. New Phytol 191:926-941

Rahman AF, Sims DA, Cordova VD, El-Masri BZ (2005) Potential of MODIS EVI and surface temperature for directly estimating perpixel ecosystem C fluxes. Geophys Res Lett 32:L19404. doi:10. 1029/2005GL024127

Richardson AD, Jenkins JP, Braswell BH, Hollinger DY, Ollinger SV, Smith M-L (2007) Use of digital webcam images to track spring green-up in a deciduous broadleaf forest. Oecologia 152:323-334

Richardson AD, Keenan TF, Migliavacca M, Ryu Y, Sonnentag O, Toomey M (2013) Climate change, phenology, and phenological control of vegetation feedbacks to the climate system. Agric For Meteorol 169:156-173
Saito K, Fujiwara A, Ishii H, Shimura S, Yano A, Kumagai Y (2004) A production of multimedia contents derived from forest environment monitoring video data. Journal of The Japanese Institute of Landscape Architecture 68(5):923-926(in Japanese with English abstract)

Saitoh TM, Nagai S, Saigusa N, Kobayashi H, Suzuki R, Nasahara KN, Muraoka H (2012) Assessing the use of camera-based indices for characterizing canopy phenology in relation to gross primary production in a deciduous broad-leaved and an evergreen coniferous forest in Japan. Ecol Inform 11:45-54

Sato M (2014) Long-term variations of budding and flowering in trees of the botanical garden of University of Tsukuba, Japan. Tsukuba J Agric Forestry 2:41-55(in Japanese with English abstract)

SCBD (2010) Global biodiversity outlook 3. Secretariat of the Convention on Biological Diversity Montreal, $94 \mathrm{pp}$

Schwartz MD, Hanes JM, Liang L (2013) Comparing carbon flux and high-resolution spring phenological measurements in a northern mixed forest. Agric For Meteorol 169:136-147

Sekizawa R, Ichii K, Kondo M (2015) Satellite-based detection of evacuation-induced land cover changes following the Fukushima Daiichi nuclear disaster. Remote Sens Lett. doi:10.1080/ 2150704X.2015.1076207

Shen M, Tang Y, Chen J, Yang X, Wang C, Cui X, Yang Y, Han L, Li L, Du J, Zhang G, Cong N (2014) Earlier-season vegetation has greater temperature sensitivity of spring phenology in northern hemisphere. PLoS One 9(2):e88178. doi:10.1371/journal.pone.0088178

Sims DA, Gamon JA (2002) Relationship between leaf pigment content and spectral reflectance across a wide range of species, leaf structures and developmental stages. Remote Sens Environ 81: 337-354

Sonnentag O, Hufkens K, Teshera-Sterne C, Young AM, Friedl M, Braswell BH, Milliman T, O'Keefe J, Richardson AD (2012) Digital repeat photography for phenological research in forest ecosystems. Agric For Meteorol 152:159-177

Sparks TH (2014) Local-scale adaptation to climate change: the village flower festival. Clim Res 60:87-89

Suzuki H (1962) The classification of Japanese climates. Geogra Rev Jpn 35(5):205-211(in Japanese with English abstract)

Suzuki R (2015) Assessment of terrestrial ecosystem function and service by remote sensing. Jpn J Ecol 65(2):125-134 (in Japanese with English abstract)

Ueta M, Kurosawa R, Saito K (2012) The data set of song frequency of forest bird. Bird Res 8:R1-R4(in Japanese with English abstract)

Wang H, Ge Q, Rutishauser T, Dai Y, Dai J (2015) Parameterization of temperature sensitivity of spring phenology and its application in explaining diverse phenological responses to temperature change. Scientific Reports 5:8833. doi:10.1038/srep08833

Xu L, Chen X (2013) Regional unified model-based leaf unfolding prediction from 1960 to 2009 across northern China. Glob Chang Biol 19:1275-1284 